\title{
Unsymmetrical Sulfides, Selenides, and Tellurides from Organoboronic Acids
}

$\mathrm{R}^{1}-\mathrm{X}-\mathrm{X}-\mathrm{R}^{1}+\begin{array}{r}\mathrm{R}^{2} \mathrm{~B}(\mathrm{OH})_{2} \\ (3 \text { equiv) }\end{array} \quad \frac{\mathrm{Cul}(5 \mathrm{~mol} \%), 2,2^{\prime} \text {-bipy (5 mol\%) }}{\mathrm{DMSO}^{2} \mathrm{H}_{2} \mathrm{O}(2: 1), \text { air, } 100{ }^{\circ} \mathrm{C}, 12-48 \mathrm{~h}} \mathrm{R}^{1}-\mathrm{X}-\mathrm{R}^{2} \quad$ up to $98 \%$ yield

$\mathrm{R}^{1}=\mathrm{Ar}, \mathrm{Bu}, \mathrm{Bn} \quad \mathrm{R}^{2}=\mathrm{Ph}, \mathrm{Ar}$, Alk, c-Alk, etc

$\mathrm{X}=\mathrm{S}, \mathrm{Se}, \mathrm{Te}$

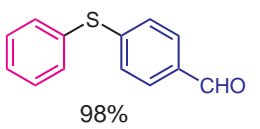

$98 \%$
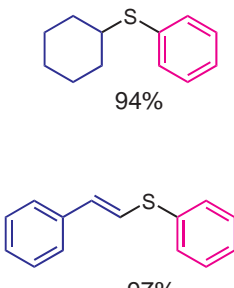

$29 \%$

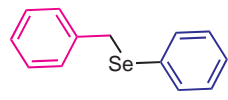

$84 \%$

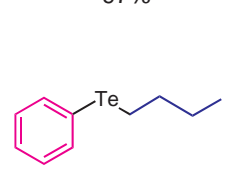

$38 \%$
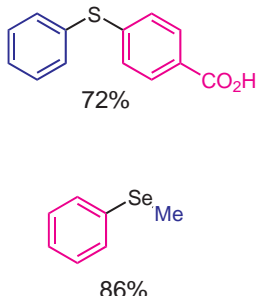

$86 \%$

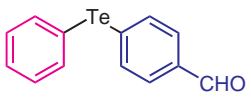

$88 \%$
Significance: This procedure allows a convenient and general transformation of various organoboronic acids into unsymmetrical sulfides, selenides, or tellurides. The mild reaction conditions ensure an excellent functional group tolerance, thus making this reaction useful for the combinatorial-like synthesis of biologically relevant molecules. The best yields are achieved with aryl chalcogenides and arylboronic acids; nevertheless, the scope of suitable substrates is quite broad. This is one of few useful methods for the preparation of unsymmetrical selenides and tellurides.
Comment: In the suggested reaction mechanism, the $\mathrm{R}^{1} \mathrm{~B}(\mathrm{OH})_{2}$ is first converted into $\mathrm{R}^{1} \mathrm{Cu}(\mathrm{I})$, which reacts with $\left(R^{2} S\right)_{2}$ or its analogue to give $R^{1} S R^{2}$ and $\mathrm{R}^{2} \mathrm{SCu}$, which after the oxidation by $\mathrm{O}_{2}$ reacts with another molecule of an organoboron compound. The reaction, therefore, requires the presence of air. Dichalcogenides are much easier to handle than the corresponding thiols or selenols, as they are not air-sensitive.

Review: For a review on the Cu-mediated arylheteroatom bond formation, see: S. V. Ley, A. W. Thomas Angew. Chem. Int. Ed. 2003, 42, 54005449. 